\title{
Experimental Design Validation of Tilting Calibration Mechanism by Using Shape Memory Alloy Spring Actuator
}

\author{
Hyun-Ung Oh, ${ }^{1}$ Myeong-Jae Lee, ${ }^{2}$ and Taegyu Kim ${ }^{1}$ \\ ${ }^{1}$ Department of Aerospace Engineering, Chosun University, 375 Seosuk-dong, Dong-gu, Gwangju 501-759, Republic of Korea \\ ${ }^{2}$ Structure and Mechanics Team, Asia Pacific Satellite Inc., 9F, 2-Dong 98, Gasan Digital 2-ro, Geumcheon-gu, \\ Seoul 08506, Republic of Korea
}

Correspondence should be addressed to Taegyu Kim; taegyu@chosun.ac.kr

Received 26 February 2017; Accepted 9 May 2017; Published 30 May 2017

Academic Editor: Christopher J. Damaren

Copyright (C) 2017 Hyun-Ung Oh et al. This is an open access article distributed under the Creative Commons Attribution License, which permits unrestricted use, distribution, and reproduction in any medium, provided the original work is properly cited.

\begin{abstract}
A tilting calibration mechanism is periodically deployed to view the reference temperature target during on-board calibration of a spaceborne imaging sensor and stowed after calibration. In the present work, we have proposed a new design strategy using a shape memory alloy (SMA) spring as an actuator that provides a fail-safe function to prevent the blocking of the main optical path when the mechanical driving part of the mechanism is stopped at a certain position during on-board calibration. Although a launch locking device was not considered in the design, this approach makes it possible to impose mechanical constraints on the driving part of the mechanism in severe launch vibration environments. The effectiveness of the proposed design was experimentally validated by a deploying and stowing function test and launch vibration environment tests such as a sine burst test, a random vibration test, and a pyroshock simulating impulse shock test. The test results demonstrated that the mechanism fulfills all the required functions for on-board calibration. The use of an SMA spring actuator was proved effective for implementing the dual function of a fail-safe in an emergency phase and a mechanical constraint on the driving part of the mechanism in severe launch vibration environment.
\end{abstract}

\section{Introduction}

To ensure long-term stability of spaceborne imaging sensors, the nonuniform output characteristics of such sensors should be periodically calibrated by using the on-board calibration system during its on-orbit mission lifetime. Several types of calibration processes for using on-board calibration devices have been proposed and used in actual space programs [1-5]. Therefore, an on-board blackbody has been used to provide a uniform and precisely known radiance temperature target to calibrate the imaging sensor [2-5]. Furthermore, a tilting mirror calibration mechanism has been employed $[6,7]$ to reflect the radiance from the blackbody on the sensors. The main function of the mechanism is periodically deployed to view the blackbody during the calibration and is stowed thereafter to avoid interference between the field of view and the main optical path. However, when the calibration mechanism stops unintentionally on the main optical path owing to a motor failure or an unexpected problem during its on-orbit operation, it is not possible to carry out the primary objective of image acquisition any more. Therefore, the implementation of a fail-safe function for the mechanism in emergency conditions should be considered in the design itself, so that the stopped mechanism does not obstruct the main optical path. Oh et al. [6] proposed using a shape memory alloy (SMA) frangibolt-type actuator to implement the fail-safe function of the calibration mechanism. This actuator is used to release the mechanical constraint between the motor shaft and mirror shaft during emergency conditions. Upon its activation, the mirror shaft connected to the motor is automatically stowed by the restoration force of a return spring. Suchman et al. [7] also proposed an MIRO calibration switch mechanism with a fail-safe function achieved by using a pin puller. Its basic principle is the same as that of the tilt mirror mechanism proposed by Oh et al. [6]. The structural safety of the mechanical driving part of both mechanisms in harsh launch vibration environments was ensured by incorporating a launch locking mechanism. 
One of the most frequently used smart material-based devices with flight heritage in actual space programs is SMAtype holding and release actuators [8-10]. Owing to their simplicity, reusability, high reliability against fatigue, and much lower shock levels than conventional pyrotechnic devices, these devices have been widely used in nonexplosive separation mechanisms for the release of mechanical constraints. However, the usage of multiseparation devices for implementing a fail-safe function and introducing mechanical constraints on the driving part of the tilting mechanism might lead to higher system complexity and increased development costs.

Therefore, in this study, we considered an SMA spring actuator to implement the dual function comprising fail-safe and mechanical constraint on the tilting calibration mechanism, although the separation device was not used in this design. The unique characteristic of an SMA spring originates in the solid-solid state phase transformation according to its operating temperature. The deformed shape of a helical SMA spring at temperature below the martensite start temperature can be reversed completely by heating the material above the austenite finish temperature [11]. Combinations of SMA springs and helical coil springs are generally used in smart actuators because they produce a high recovery force during the heating process $[12,13]$ and are compressed again by the recovery force induced by the coil springs during the cooling process. Pan and Huang [14] performed a systematical study on the SMA based biased actuator upon thermal cycling. They reported that the transformation temperature interval increases, while temperature hysteresis decreases as the geometry of the SMA and/or stiffness of the coil spring increases in a biased SMA actuator. Using this approach, it is possible to substitute the usage of multiseparation devices. This is a salient feature of the mechanism design proposed in this study.

In this paper, the design methodology of the tilting mechanism using SMA springs has been introduced. To verify the effectiveness of the mechanism, we performed operational function tests of the mechanism, including failsafe operation. Furthermore, the mechanism was exposed to the conditions of qualification level of launch environment vibrations through tests such as sine burst, random vibration, and shock tests to confirm the faultless operation of the mechanism following these mechanical tests. The test results demonstrated that the design approach using an SMA spring is feasible for realizing the design goal of implementing the dual function in the on-board tilting calibration mechanism.

\section{Spaceborne Tilting Calibration Mechanism}

2.1. Operation Modes and Design Drivers. Figure 1 shows the on-board calibration process using the tilting calibration mechanism proposed in this study. A blackbody to provide the reference radiance temperature necessary for sensor calibration is mounted directly on the tilting mechanism. The required function modes for a normal operation of the mechanism during on-board calibration are the deploying and stowing modes with the fail-safe mode being required for an emergency phase. In the deploying mode, the calibration mechanism comprising a blackbody is deployed to provide a reference radiance temperature to the imaging sensor as shown in Figure 1(a). After completing the on-board calibration of the imaging sensor, the mechanism is stowed, thereby securing the main optical path again for the execution of image acquisition, as shown in Figure 1(b). If, in the image mode, the deployed mechanism is stalled at a certain position on the main optical path, there is interference between the main optical path and the mechanism. This prevents the image sensor from carrying out any image acquisition. The fail-safe mode for emergency condition does not allow an intervention, thereby ensuring that any such obstruction is removed from the main optical path as shown in Figure 1(c).

The main design driver is to implement the aforementioned functions of deploying, stowing, and fail-safe on the tilting mechanism. Moreover, the mechanism shall be designed such that the structural safety of the mechanical driving part is guaranteed in harsh launch vibration environments by incorporating the function of a launch constraint. This function including a fail-safe for emergency conditions can be achieved by applying separation devices as proposed in a previous study [6]. However, using the multiseparation devices led to increased system complexity and lower reliability; additionally, the total mass of the system increased as well. Furthermore, if the launch locking mechanism fails to successfully release the launch constraint, it is not possible to perform the on-board calibration anymore. The main design objective of this study is therefore to implement the dual function of a mechanical constraint and a fail-safe within the mechanism for both launch and emergency phases without the use of additional separation devices.

\subsection{Design Description of the Tilting Calibration Mechanism} Using SMA Spring Actuator. SMA is a class of smart materials with unique properties, which include shape memory effects, pseudo elastic effects, high damping characteristics, high reliability with respect to fatigue and corrosion resistance, and an electric resistance effect [11]. A large deformation of SMA can be reversed by changes in temperature or stress. Recently, SMA have found numerous applications in different fields of aerospace engineering, particularly in nonexplosive-type actuators for hold-and-release mechanisms [8-10].

In this research, to achieve the design goal of the onboard tilting mechanism, we focused on the smart material of the SMA spring actuator as shown in Figure 2. The SMA spring based on the shape memory alloy effect generates a restoration force and a large stroke during the heating process. A deformation of an SMA spring caused at a temperature below the martensite start temperature can be reversed completely by heating the material above the austenite finish temperature [11]. The SMA spring can also be used as a mechanical two-way actuator as described in [16] when it is used in combination with a helical coil spring as shown in Figure 2(b). For example, a coil spring is able to completely revert the SMA spring to its compressed length in the martensite phase. On the other hand, the coil spring can be completely compressed by the restoration force generated 


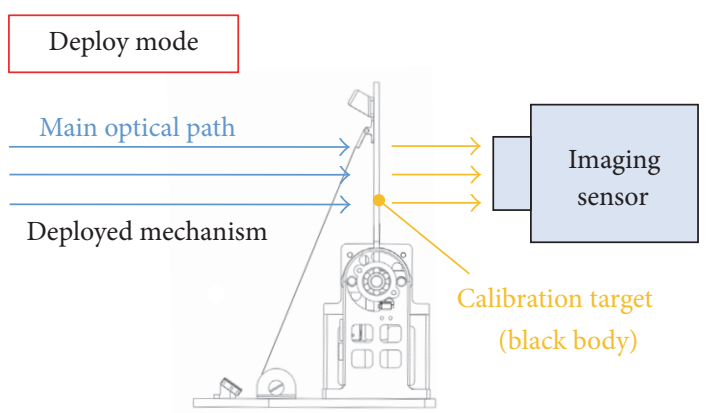

(a)

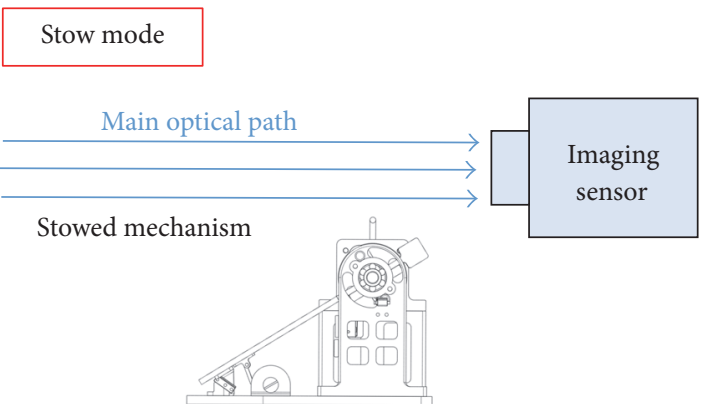

(b)

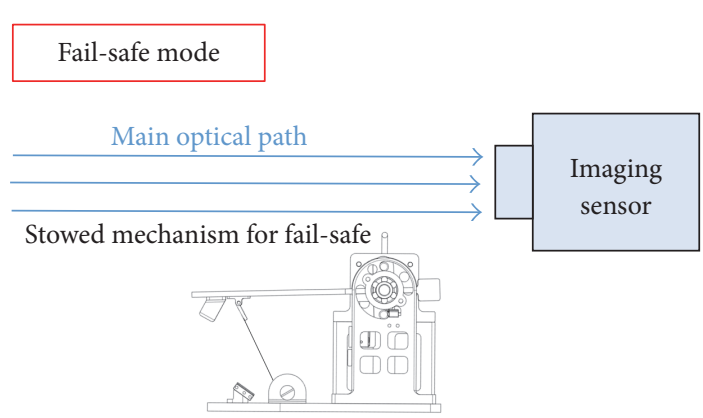

(c)

FIGURE 1: Operation concept of on-board calibration using the tilting calibration mechanism.

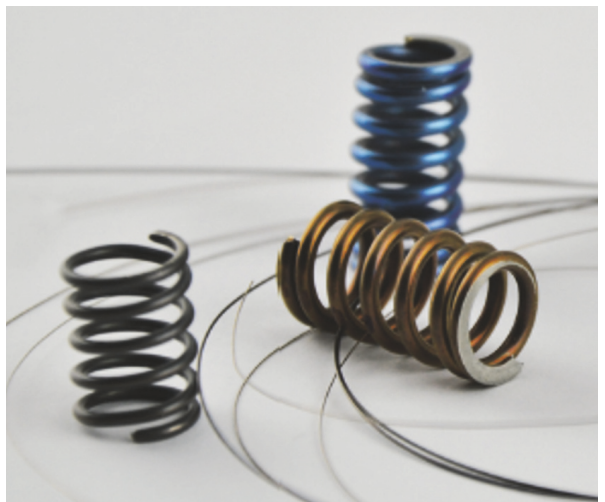

(a)

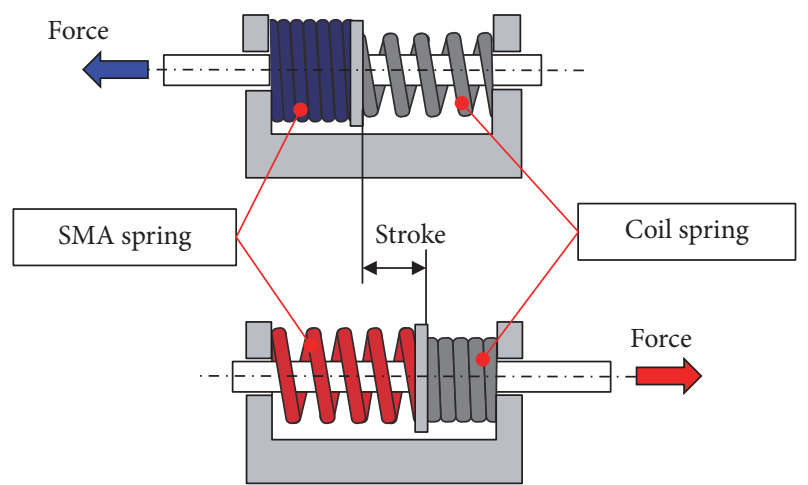

(b)

FIGURE 2: SMA spring actuator [15].

by the SMA spring during the heat-up phase. In this study, this mechanical two-way interaction characteristic of the SMA spring actuator was applied to achieve the design goal of the calibration mechanism.

Figure 3 shows the mechanical configuration of the onboard tilting calibration mechanism proposed in this study. The mechanism comprises primarily the base structure module, the driving structure module, and the actuator module. The actuator module is used to activate the stowing and deploying of the driving structure module during the onboard calibration. It consists of a stepper motor, a coupling, and locking pin holder bracket with two holes. The driving structure module consists of the locking pin housing with two locking pins combined with the mechanical two-way SMA spring actuator, a counterweight for the mass balancing of the driving part, and a tilting plate to mount the calibration equipment, such as a mirror or a blackbody. The base structure module consists of a base frame, ball bearing brackets, a constant-force spring to apply a restoration force on the mechanical driving part during fail-safe operation, and limit switches to monitor and judge the status of each mission mode.

Figure 4 shows the operating principle of the calibration mechanism for each operation phase. In the launch phase, the calibration mechanism maintains a stowed position as shown in Figure 4(a). In this condition, it is imperative to secure the structural safety of the driving structure module in a launch mechanical environment. For this, the position of 


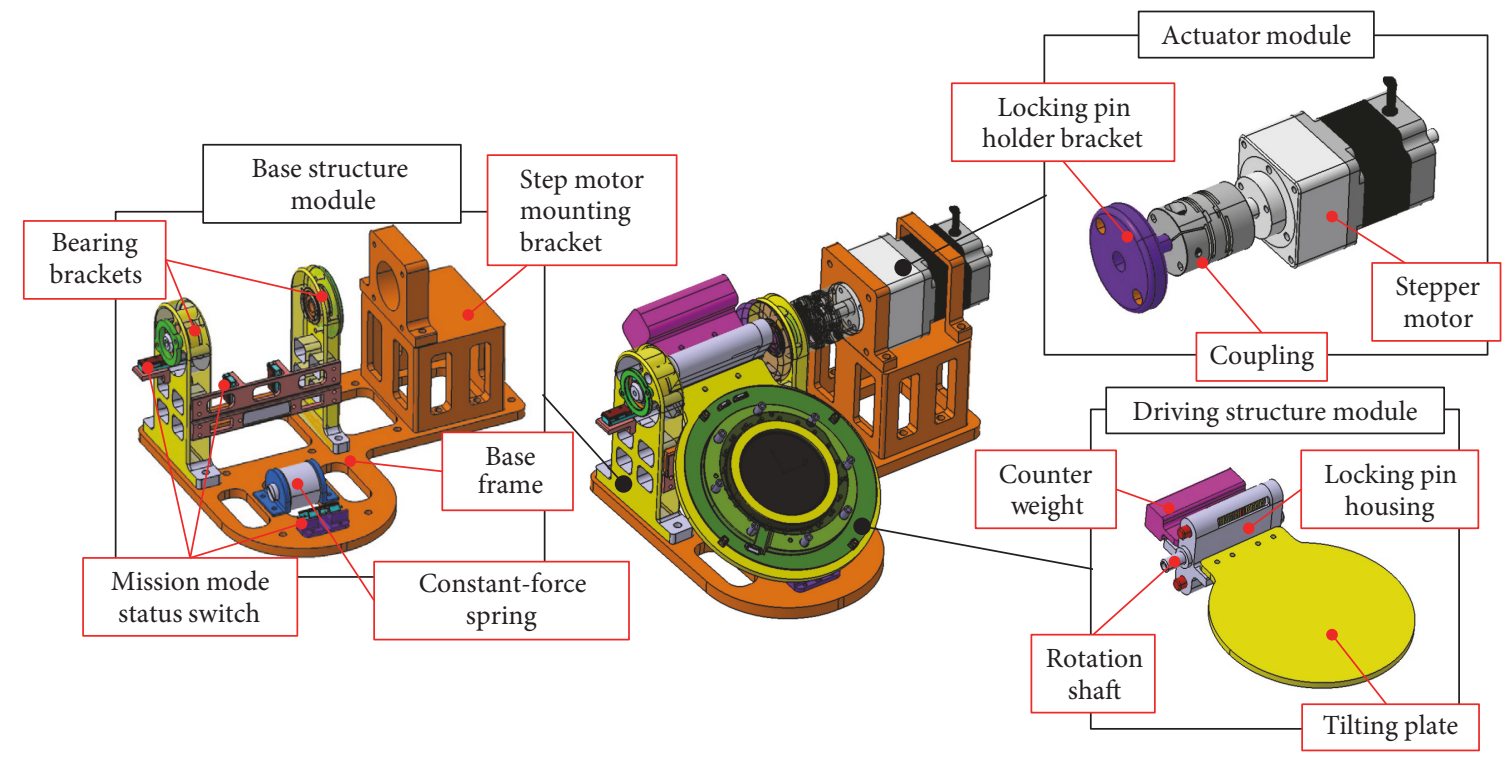

FIgURE 3: Composition of the tilting calibration mechanism.

the two locking pins in combination with the SMA springs and helical coil springs inside the locking pin housing is important to impose a mechanical constraint on the driving structure module in a launch vibration environment. The figure also shows the position of the locking pins marked on the locking pin holder bracket connected to the stepper motor and a bearing bracket located on the opposite side of the motor. The two holes on the locking pin holder bracket maintain the shifted angle position with respect to the locking holes on the bearing brackets. Hence, the two locking pins are compressed to the right side of the bearing bracket and locked in the launch locking holes on the bracket as shown in Figure 4(a). This makes it possible to implement a mechanical constraint on the rotational direction of the mechanical driving structure module in launch environments. In such a situation, there is no mechanical connection between the motor shaft and the driving structure module.

In the calibration phase, the release of the mechanical constraint on the driving structure module is achieved by the in-orbit activation of the stepper motor. When the two locking pins having surface contact with the locking pin holder brackets as shown in Figure 4(a) coincide with the two holes on the locking pin holder bracket during its rotational movement initiated by the motor activation, the locking pins mechanically locked in the locking holes on the right side of the bearing structure in the launch phase are automatically shifted by the restoration force of the coil spring to the holes on the locking pin holder bracket on the motor as shown in Figure 4(b). Therefore, after the release action, the motor is able to transmit the rotational torque to the driving structure module and thus apply both deploying and stowing functions on the mechanism. During the execution of onboard calibrations, the SMA springs are compressed to the left side of the locking pin holder bracket by the restoration force of the coil spring.
According to European Cooperation for Space Standardization [17], the mechanism should consider additional design improvements to remove a potentially critical problem if the value of criticality is greater than six, even though the mechanism meets the allocated reliability. In this regard, obstruction of the main optical path due to an unexpected problem during the on-orbit operation of the mechanism is viewed as a critical item for an image acquisition. The criticality number obtained from a severity number of three and a probability number of three is nine if obstruction of the main optical path is considered as a critical item. The motor can be designed with redundancy combined with a mechanical latch, so that when one motor fails, the other takes its function. This ensures that the calibration mode continues operating. However, this makes the system complex and affects the reliability of the mechanism. To avoid design complexity and a potentially critical failure, a fail-safe function using SMA spring actuators was integrated in the mechanism to remove the stopped tilt mirror from the main optical path. In the emergency phase, heating of the compressed SMA springs generates a recovery force to overcome the coil spring force. As a result, the locking pins are shifted to the right side of the dedicated fail-safe holes on the bearing brackets as shown in Figure 4(c). Subsequently, the driving part is automatically stowed along the fail-safe holes on the bearing structure by the restoration force of the constant-force spring. This results in the mechanical constraint between the motor and the locking pins on the driving part being released from the locking pin holder bracket, with the driving structure module being automatically stowed to a dedicated position for the fail-safe as shown in Figure 4(c). For a conventional calibration mechanism investigated by Oh et al. [6], the mechanism loses its main function of the calibration once the separation device is activated during an emergency condition. In contrast, the calibration mechanism 


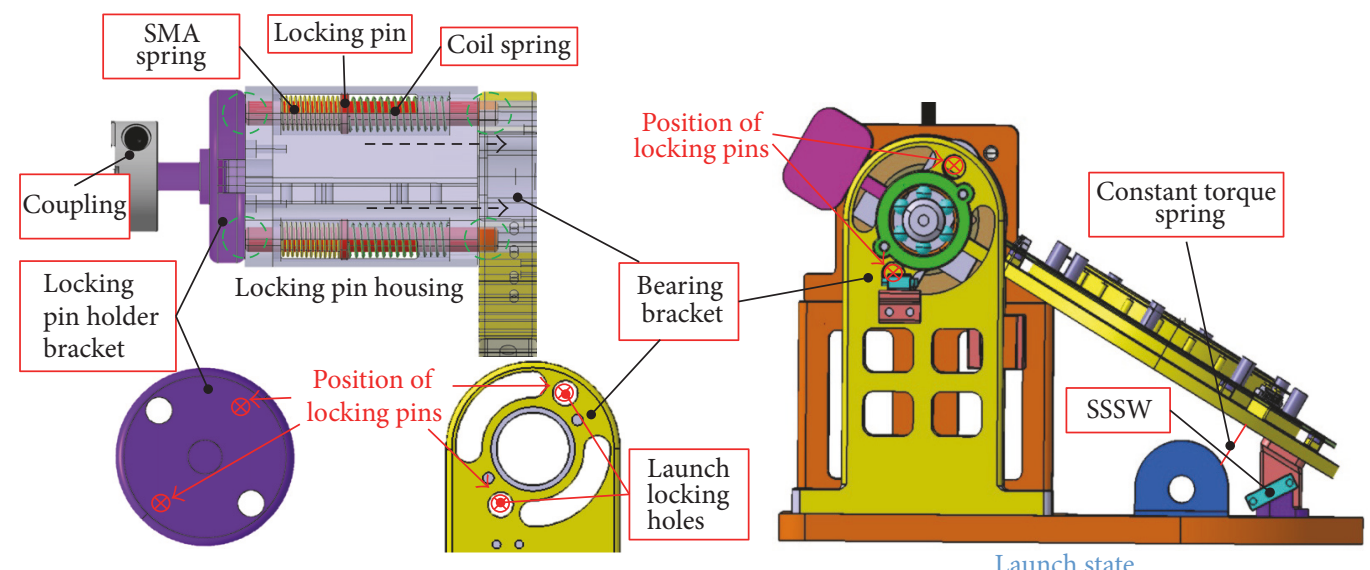

(a)

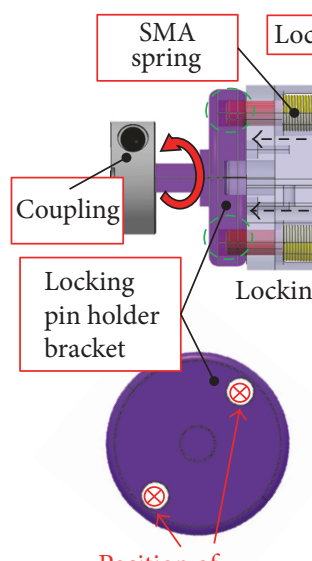

Position of locking pins

(c) (b)

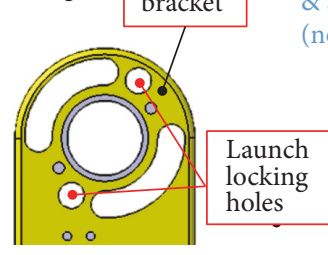

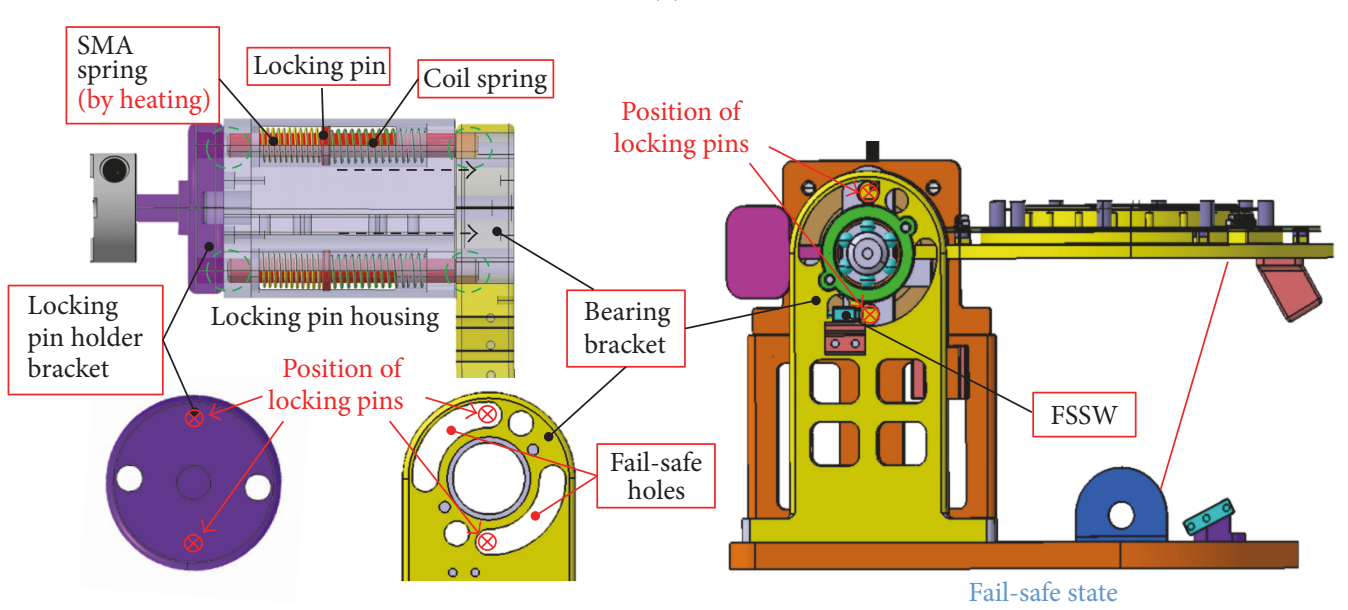

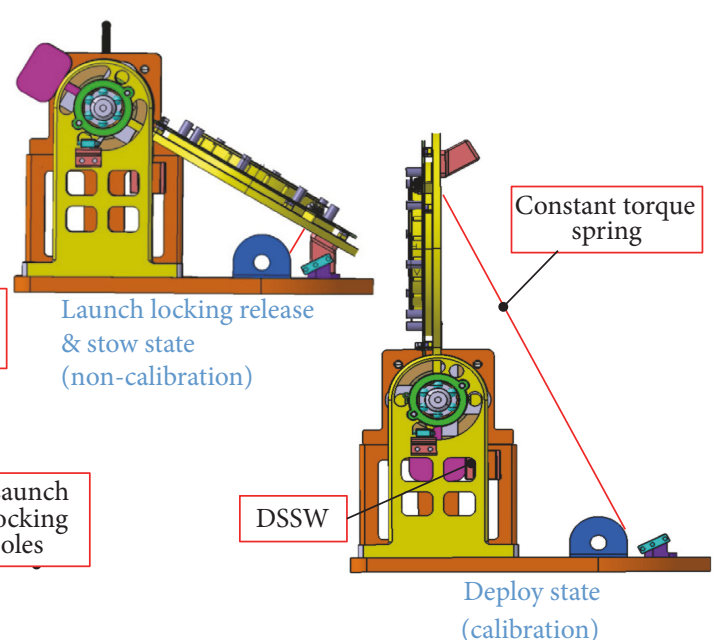

FIGURE 4: Operating principle of the tilting calibration mechanism for each operation phase ((a) launch phase, (b) launch locking release and on-board calibration phase, and (c) emergency phase). 
proposed in this study can recover its calibration function again if it was judged that there was no critical failure on the motor through failure, detection, isolation, and recovery (FDIR) process. The released locking pins positioned in the fail-safe holes on the right side of the bearing bracket can be automatically shifted to the holes on the locking pin holder bracket on the motor side. The shifting of locking pins transmits the rotational torque to the driving structure by initiating a rotational movement of the motor upon cooling of the SMA spring below the martensite temperature.

The successful operation of the mechanism is monitored by the limit status switches consisting of stow status switch (SSSW), deployment status switch (DSSW), and emergency status switch (ESSW) for each mode. DSSW also provides information for judging the transition to the holding torque of the motor when the limit switch is turned on. For redundancy, two limit switches were implemented.

Figure 5 shows the development model of the on-board tilting mechanism to validate the effectiveness of the design through operational function test and launch environment tests, such as sine burst test, random vibration test, and shock test. In the development model of the mechanism, a dummy plate of the driving structure module was used to simulate the mass and the center of gravity of the on-board blackbody. The other parts, including the SMA springs, were the same as in the flight model of the mechanism. The total mass of the mechanism is $4.97 \mathrm{~kg}$ with a maximum volume of $308.5 \times 225 \times 300 \mathrm{~mm}^{3}$ when its driving structure module is fully deployed for the execution of on-board calibration. The deployed position of the mechanism is maintained by the holding torque of the motor during the calibration time of 3 s. To control the stepper motor accurately, a microstepping control function is programed in the motor driver.

For the design of the calibration mechanism, we derived the torque budget using the ECSS standard rule [18]. The required torque for a step motor should be larger than or equal to the sum of the external torque from the limit switches, the ball bearings, and constant-force springs with some margin as follows:

$$
T_{m} \geq 2\left(1.2 T_{l}+1.2 T_{c}+3 T_{b}\right)
$$

where $T_{m}$ is the required motor torque; $T_{l}$ is the limit switch torque; $T_{c}$ is the constant-force spring torque; $T_{b}$ is the bearing friction torque. For the fail-safe function, the constant-force spring torque of $T_{c}$ should be larger than

$$
T_{c} \geq T_{l}+T_{f}+T_{b}
$$

where $T_{f}$ is the rotational friction torque between the locking pin and the fail-safe holes on the bearing bracket. Table 1 summarizes the torque budget of the tilting calibration mechanism and specification of the hardware selected for the mechanism. The use of an SMA spring in combination with a helical coil spring is important for the implementation of the fail-safe function in the mechanism. Table 2 lists the specifications of the SMA spring (SAES Getters Group, SmartFlex015) [15] and the helical coil spring used in the mechanical two-way actuator in emergency conditions.
TABLE 1: Summary of torque budget of the tilting calibration mechanism.

\begin{tabular}{lc}
\hline Torque & Values $(\mathrm{Nm})$ \\
\hline$T_{l}$ & 0.0253 \\
$T_{c}$ & 0.7 \\
$T_{b}$ & 0.042 \\
$T_{f}$ & 0.4 \\
$T_{m}$ & 2.05 \\
\hline
\end{tabular}

TABLE 2: Specifications of the SMA spring and helical coil spring $\left(M_{s}\right.$ : martensite start temperature, $M_{f}$ : martensite finish temperature, $A_{s}$ : austenite start temperature, and $A_{f}$ austenite finish temperature).

\begin{tabular}{lc}
\hline Spring type & Compression \\
\hline & SMA spring \\
Wire diameter $(\mathrm{mm})$ & 1.5 \\
Spring diameter $(\mathrm{mm})$ & 10.3 \\
Free length $(\mathrm{mm})$ & 26 \\
Typical force $(\mathrm{N})$ & $10-15$ \\
Typical stroke $(\mathrm{mm})$ & $8-12$ \\
Activation temperature $\left({ }^{\circ} \mathrm{C}\right)$ & $95-100$ \\
$M_{s}, M_{f}, A_{s}, A_{f}\left({ }^{\circ} \mathrm{C}\right)$ & $75,60,95,105$ \\
\hline & \\
Wire diameter $(\mathrm{mm})$ & 1.2 \\
Spring diameter $(\mathrm{mm})$ & 16 \\
Free length $(\mathrm{mm})$ & 50 \\
Spring constant $(\mathrm{N} / \mathrm{mm})$ & 0.5 \\
Maximum load $(\mathrm{N})$ & 10.8 \\
Allowable strain $(\%)$ & 45 \\
\hline
\end{tabular}

\section{Experimental Validation of Test Results}

To validate the effectiveness of the proposed design of the tilting calibration mechanism, we performed operational function tests such as deploying, stowing, and fail-safe. The functional test results prior to a sine burst test, random vibration test, and shock test to check the structural safety of the mechanism in a launch environment were compared with the functions after the launch environment test. The target angle for judging successful deployment measured from the stowing position of the mechanism was $118^{\circ} \pm$ $0.35^{\circ}$, and the required stowing angle to avoid interference with the main optical path was less than $35^{\circ}$. A total of seven angle measurement tests were conducted to ensure the functionality of the mechanism. The tests were conducted at $20^{\circ} \mathrm{C}$ in an ambient environment.

Figure 6 shows an example of operational function test results for each of the stowing, deploying, and fail-safe operation modes. To judge the successful operation of the mechanism, the deploying and stowing angles in each phase were measured using an encoder (Lika Electronic Co., I65-L$10000 Z C U 1 E L 2)$, attached on the rotational axis of the mechanism as shown in Figure 6. This was intentionally attached only for the deploying and stowing angle measurement. 


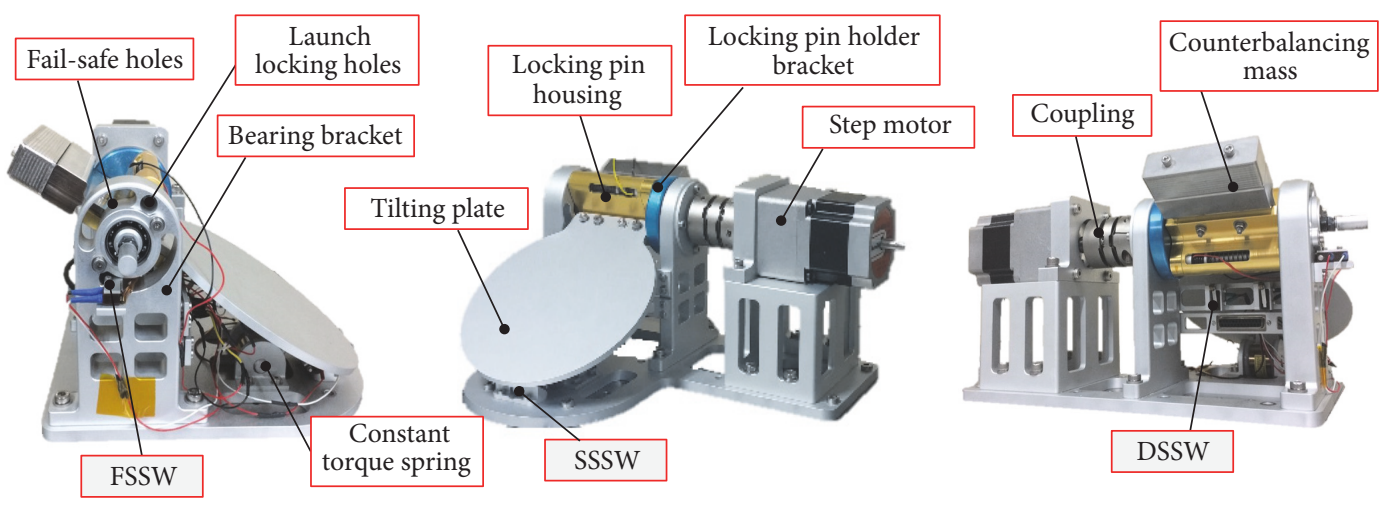

FIgURE 5: Manufactured development model of the tilting calibration mechanism.
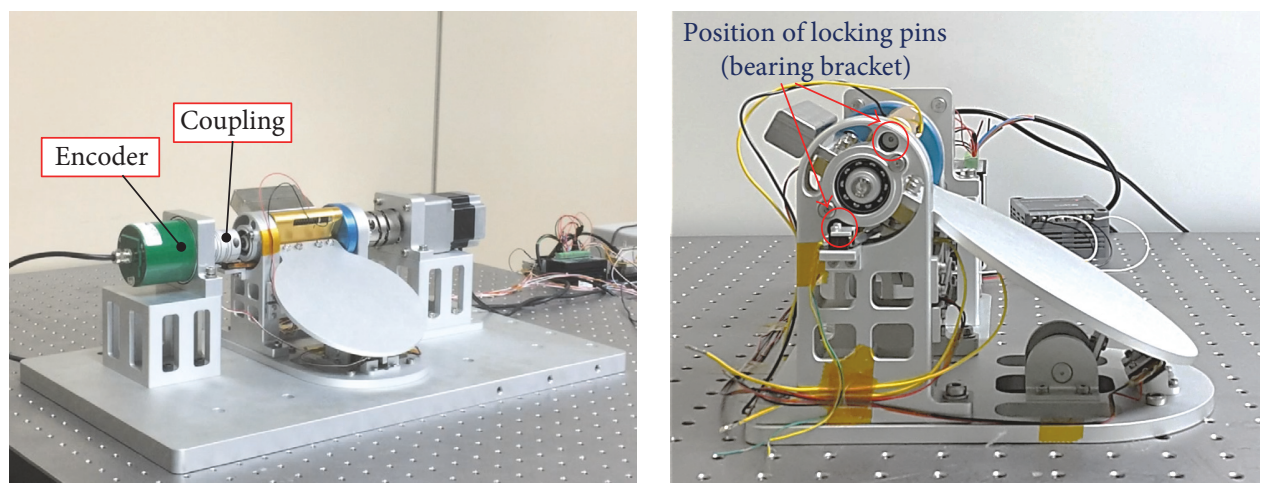

(a)
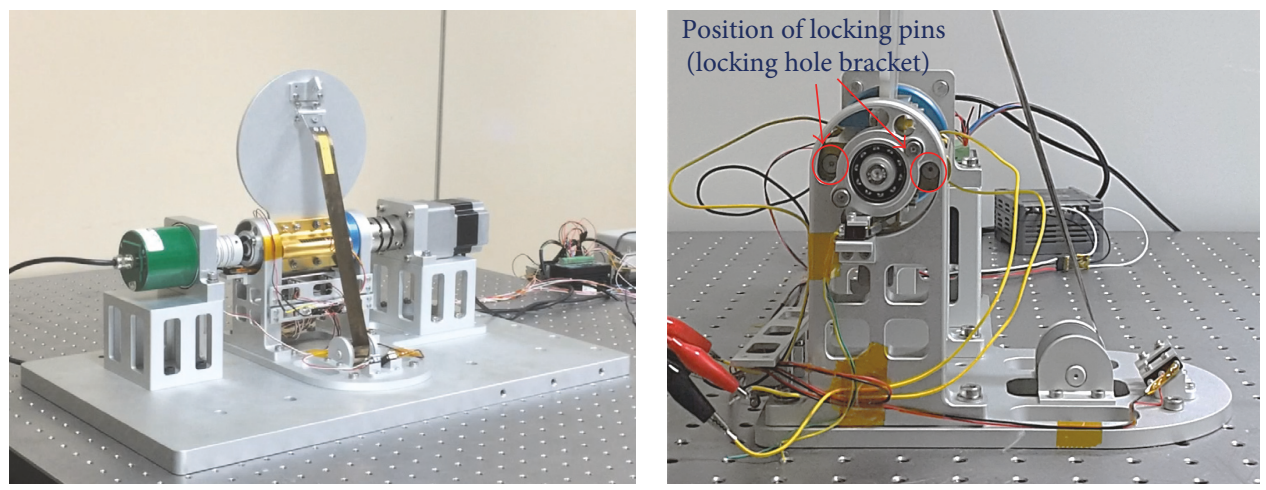

(b)
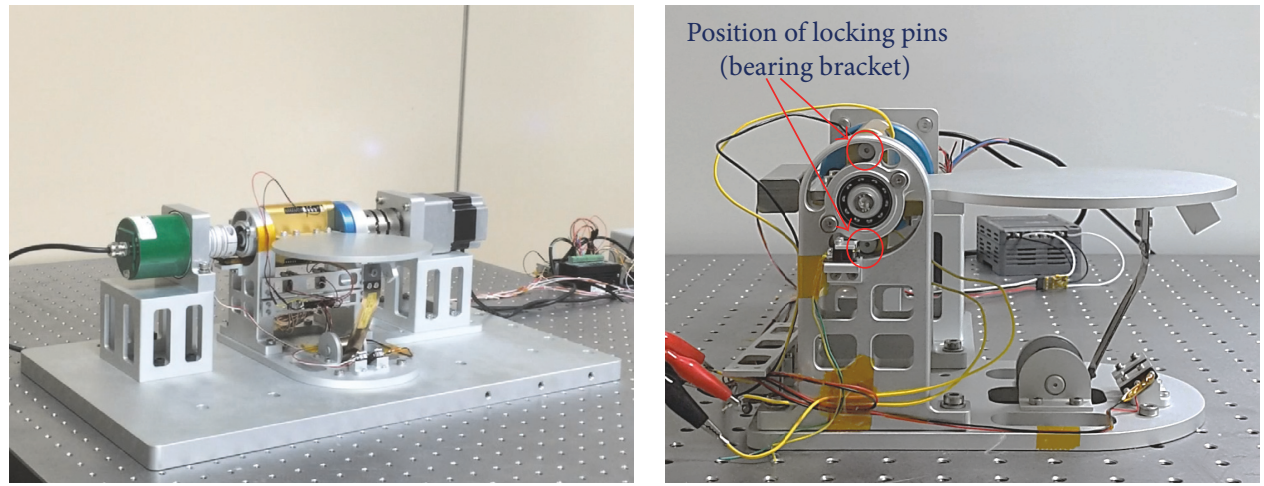

(c)

FIGURE 6: Example of operational function test results ((a) stowing mode, (b) deploying mode, and (c) fail-safe mode). 

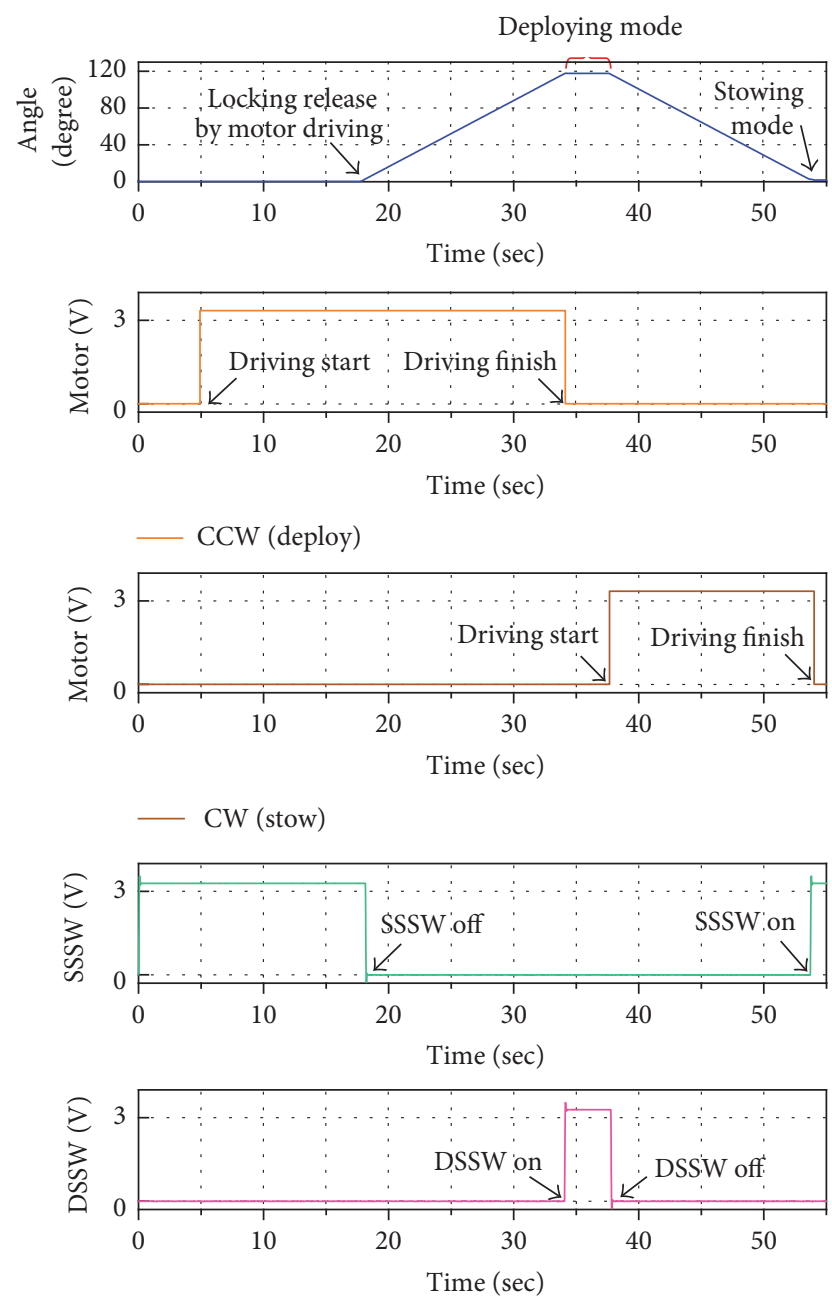

FIGURE 7: Time histories obtained from the launch locking releasing, stowing, and deploying function tests.

Figure 7 shows the time histories for the measured deploying and stowing angles and voltage signals from the motor and switches obtained during the launch lock release test, and stowing and deploying function tests. The configuration of the stowing mode of the mechanism, as shown in Figure 6(a), is the same as that of the launch phase. In this condition, the rotational movement of the driving structure module is locked by the locking pins as defined by the operating principle in Figure 4(a). The function test result shown in Figure 7 includes a launch lock release function test of the mechanism. The test result indicates that the launch constraint is successfully released after $13 \mathrm{~s}$ after motor activation, as shown in the time history of the counterclockwise motor signal. The mechanism is thus able to transmit the rotational torque for implementing the deploying function for the on-board calibration of the image sensor as defined by the operating principle in Figure 4(b). Therefore, the driving structure module of the mechanism maintains the deploying configuration with the help of the holding torque of the motor. After calibration, the stepper motor activation ensures that the mechanism returns to the
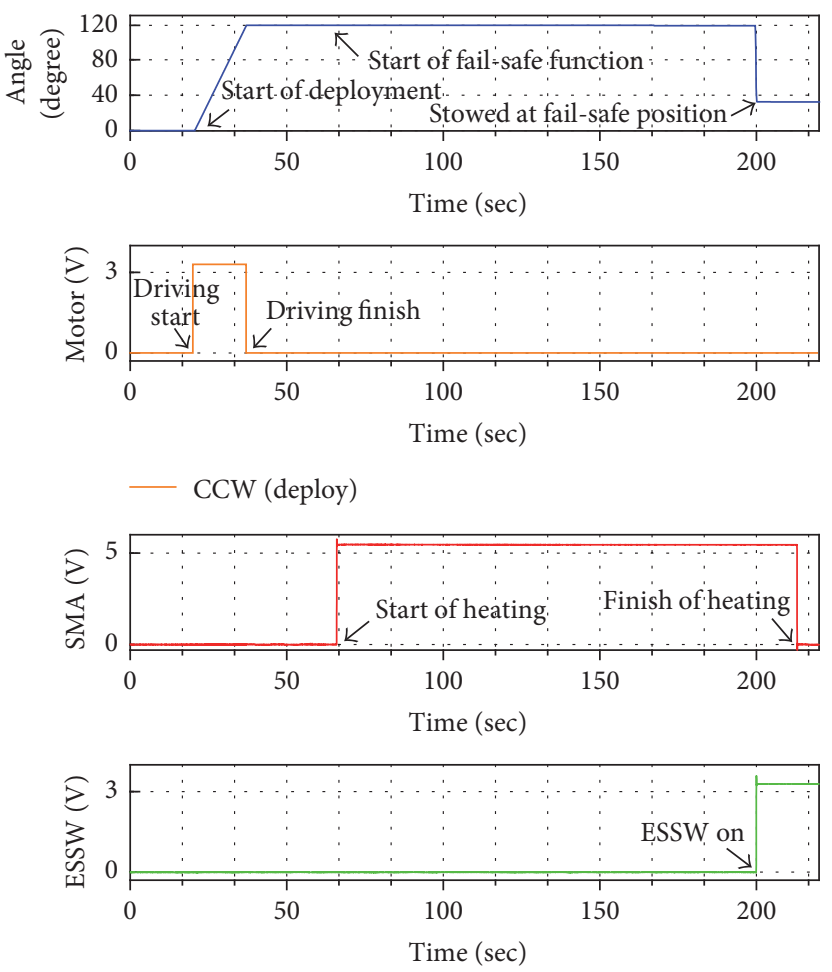

FIGURE 8: Time histories obtained from the fail-safe function test by using SMA spring actuator.

stowed position, as shown in Figure 6(a). The signals from the SSSW and DSSW in Figure 7 also show the successful mission mode execution from the launch release to stowing of the mechanism.

Figure 8 shows the time histories for the measured angle, input voltage to the SMA spring actuator, and voltage signals from the motor and switches obtained during the failsafe function test performed under the assumption that the deployed mechanism was stalled on the main optical path during on-board calibration. To check the functionality of fail-safe, an input voltage of $5.5 \mathrm{~V}$ and a current of $4.5 \mathrm{~A}$ were applied to the SMA spring actuators approximately $40 \mathrm{~s}$ after the mechanism was fully deployed. The time profile of the switch signal for the ESSW shows that the mechanical constraint between the motor shaft and the driving structure module was released upon activation of the SMA spring actuator as defined by its operating principle in Figure 4(c). The deployed mechanism was successfully stowed to the designated position for the fail-safe function by the restoration force of the constant-force spring as shown in Figure 6(c). After the start of heating at an ambient temperature of $20^{\circ} \mathrm{C}$, it took approximately $130 \mathrm{~s}$ for the temperature of the actuator to reach approximately $100^{\circ} \mathrm{C}$, at which point the mechanical constraint was released. The release time of the mechanism should be improved under vacuum conditions compared to air conditions [19]. The actual temperature distribution on the SMA spring actuators was not directly measured in the test because they were installed inside of the locking pin housing. In the test, we just measured the release time of 


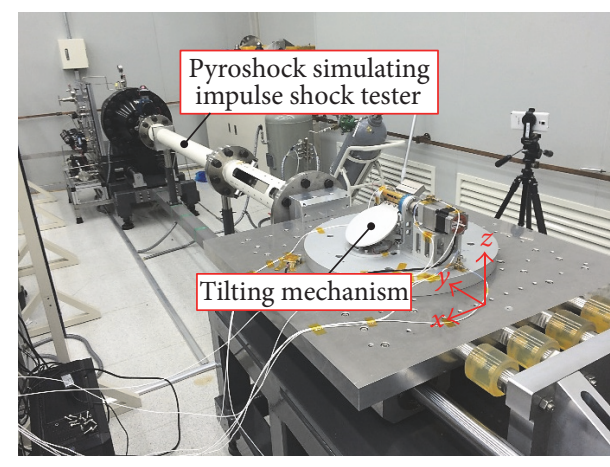

(a)

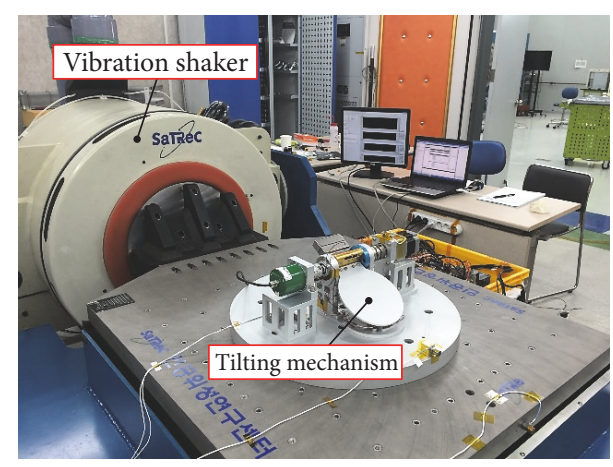

(b)

FigURE 9: Launch environment test set-up ((a) pyroshock simulating impulse shock test, (b) vibration test).

the mechanism after starting of heating. The geometry effect in triggering the actuation of NiTi shape memory alloys by constant and cyclic electrical current was investigated in [20, 21]. These operational function test results indicate that all the required functions for the on-board calibration mechanism were successfully demonstrated.

To guarantee the structural safety and successful on-orbit operation of the calibration mechanism in severe launch environments, launch vibration tests such as sine burst test, random vibration test, and shock test were carried out under qualification level. The main objectives of the tests were to verify the effectiveness of the mechanism design and to judge the suitability of the proposed method for use in space programs before actual flight demonstrations take place.

Figure 9 shows the launch environment test set-up for the shock test and the vibration test for the mechanism. The qualification test specifications have been summarized in Table 3. An accelerometer sensor, which is used to apply input test loads, was mounted on the test fixture. The output responses of the mechanism were monitored using accelerometers attached to the motor and the bearing bracket. The effectiveness of the mechanism design was validated by comparing the variation in the measured angle values of the mechanism before and after the tests.

Figure 10 shows an example of a sine burst test result for the mechanism along the $z$-axis. The output acceleration was measured at the motor mounting bracket. In the sine burst test, a design load of $40 \mathrm{~g}$ was applied to the mechanism along each axis in the test method of employing ramp-up and rampdown for seven cycles. In addition, random vibration tests for each axis were performed according to the qualification test specifications listed in Table 3. Figure 11 shows the random vibration test results for the mechanism for each axis. With respect to a test input of $12.44 G_{\mathrm{rms}}$, the measured $G_{\mathrm{rms}}$ values on the motor mounting were 32.1, 38.1, and 29.2, respectively, for each axis. Figure 12 shows an example of a shock test result obtained from a pyroshock simulating test using an impulse shock generator as shown in Figure 9(a). The figure shows the input profile of the SRS (Shock Response Spectrum) measured at the base plate where the mechanism was mounted, and a maximum $1000 \mathrm{~g}$ of SRS was applied to the mechanism.
TABLE 3: Summary of qualification test specifications.

(a) Shock test

\begin{tabular}{lc}
\hline Frequency $(\mathrm{Hz})$ & SRS $(\mathrm{g})$ \\
\hline 100 & 20 \\
1500 & 1000 \\
10000 & 1000 \\
\hline
\end{tabular}

(b) Sine Burst Test

\begin{tabular}{lc}
\hline Amplitude (g) & Sweep \\
\hline 40 & Ramp-up/ramp-down: 7 cycles \\
\hline
\end{tabular}

(c) Random Vibration Test

\begin{tabular}{lccc}
\hline Frequency $(\mathrm{Hz})$ & PSD $\left(\mathrm{g}^{2} / \mathrm{Hz}\right)$ & Overall grms & Duration \\
\hline 20 & 0.005 & & \\
50 & 0.150 & $12.44 \mathrm{~g}$ & $60 \mathrm{sec}$ \\
800 & 0.150 & & \\
2000 & 0.005 & & \\
\hline
\end{tabular}

Figure 13 shows the measured deploying angle values of the mechanism before and after launch environment tests at the qualification level. The maximum variation in the value of the angles was less than $0.094 \%$, which meets the requirement of the variation being within $5 \%$ of the nominal target angle requirement of $118^{\circ} \pm 0.35^{\circ}$ from the stowed position as shown in Figure 6(a). Figure 14 shows the measured stowing angle values of the mechanism before and after launch environment tests. The results indicate that the stowing angle increased slightly after the random vibration test compared to the results obtained before the random vibration test. The values ranges are from $1.4^{\circ}$ to $1.8^{\circ}$. Considering the requirement of less than $35^{\circ}$ for not obstructing the main optical path, there is enough margin. Figure 15 shows the measured stowing angle values of the mechanism after execution of fail-safe function before and after launch environment tests. A total of three fail-safe tests were conducted before and after the vibration test to evaluate the validity of the fail-safe function using SMA spring actuators. The release time of the mechanism after activation of the SMA spring actuators at the ambient temperature of $20^{\circ} \mathrm{C}$ was also plotted in Figure 14 . 


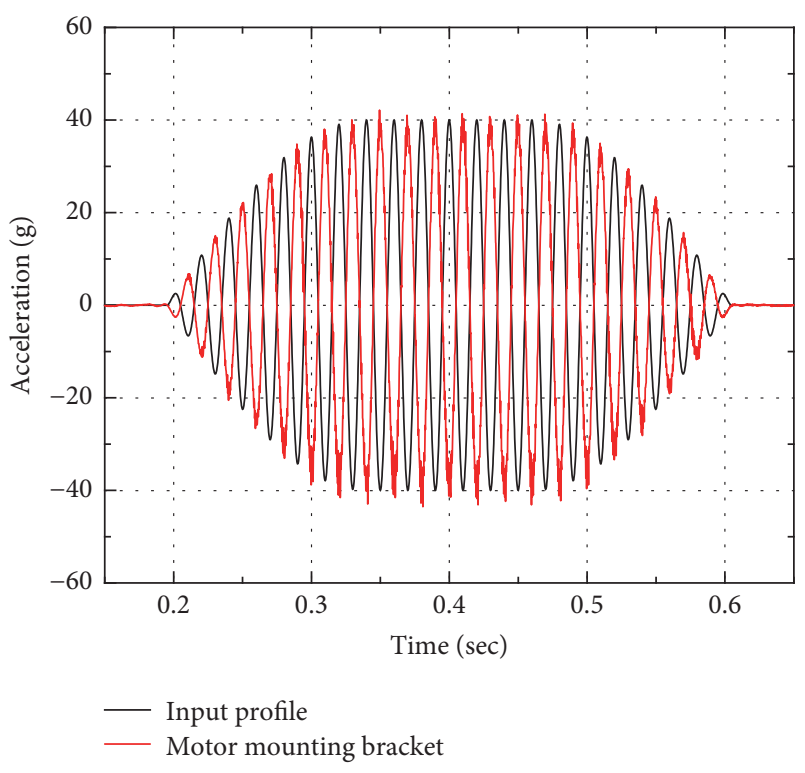

FIgURE 10: Example of the sine burst test result.

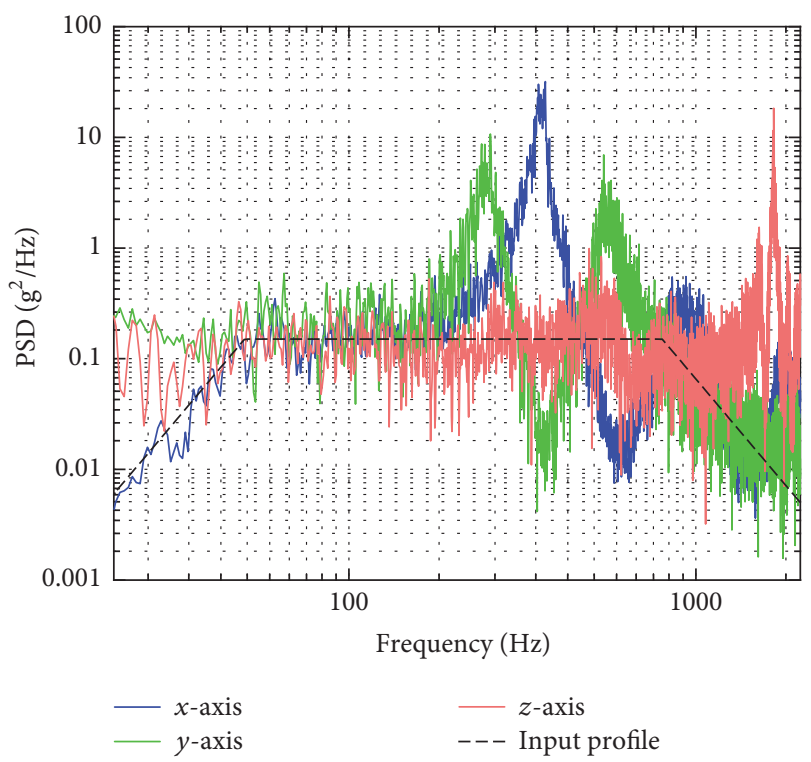

Figure 11: Example of the random vibration test result.

These fail-safe tests were successfully performed as shown in Figure 6(c), and the angle measurement results of the fail-safe were within a tolerance of $32.5^{\circ} \pm 0.4^{\circ}$. This indicates that the stowed mechanism after fail-safe did not interfere with the main optical path. The measured release times when the input power was $25 \mathrm{~W}$ were less than $180 \mathrm{~s}$ with a little variation in ambient temperature conditions. The release time can be reduced by increasing the input power, while in vacuum it should be faster than in ambient conditions [19]. The test results indicate that the current design of the mechanism can guarantee a reliable cut through the mechanical constraint between the motor and the driving structure module in emergency conditions. The test results also indicate that using

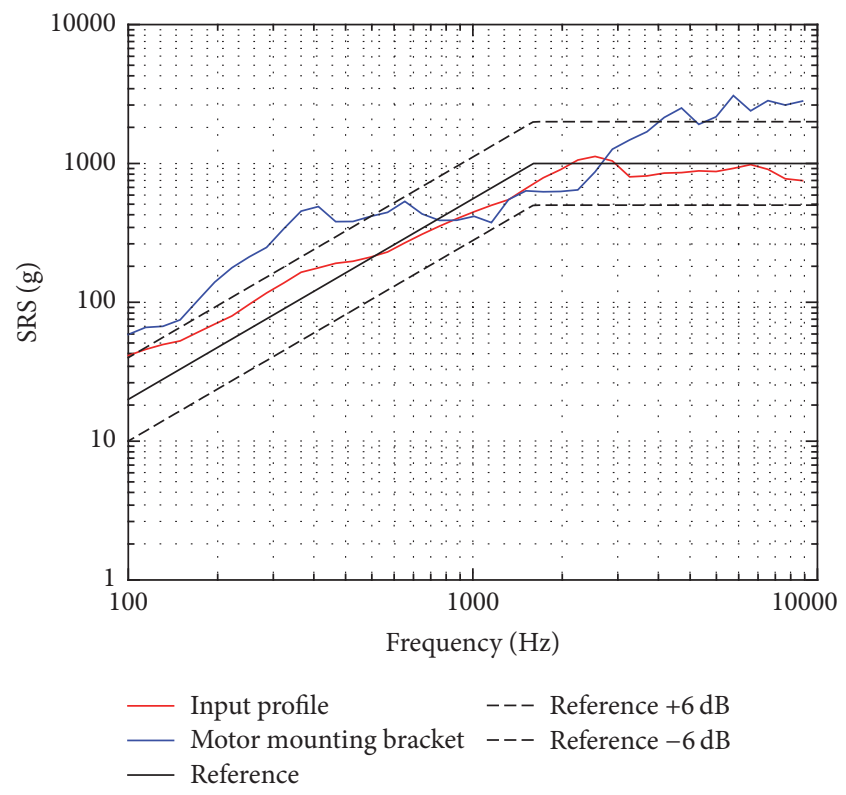

FIGURE 12: Example of the pyroshock simulating impulse shock test result.

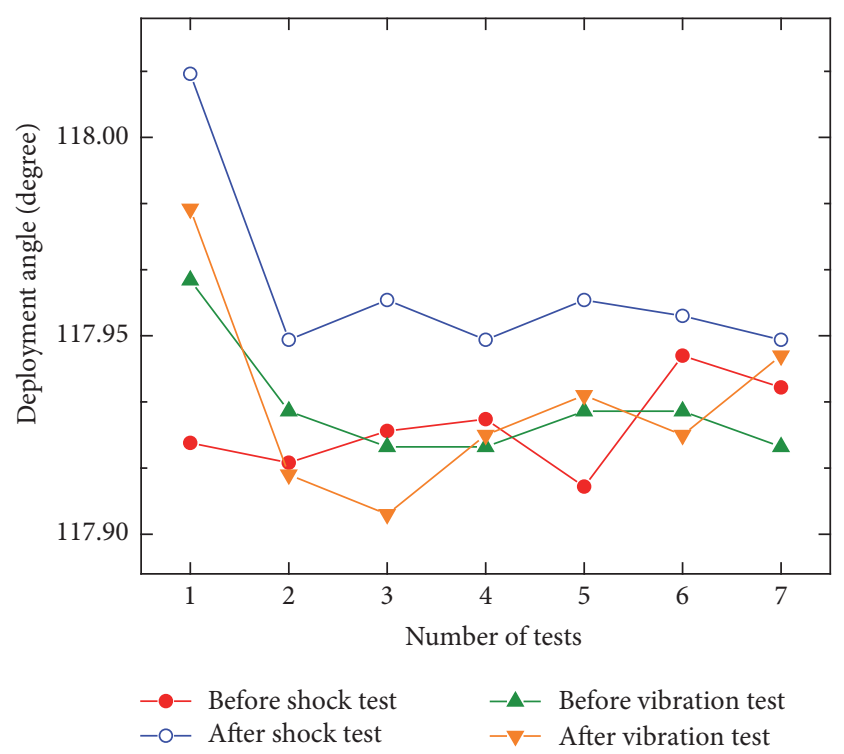

FIGURE 13: Measured deploying angle values before and after launch environment tests.

an SMA spring actuator is effective in applying the fail-safe and launch locking functions to the mechanism. The function test results shown in Figures 13, 14, and 15 demonstrate that all the functional requirements could be successfully verified after the launch vibration tests performed at qualification level. This can also ensure the survivability of the mechanism in launch environments

\section{Conclusion}

The tilting calibration mechanism using SMA spring actuators proposed in this study provides the dual function 


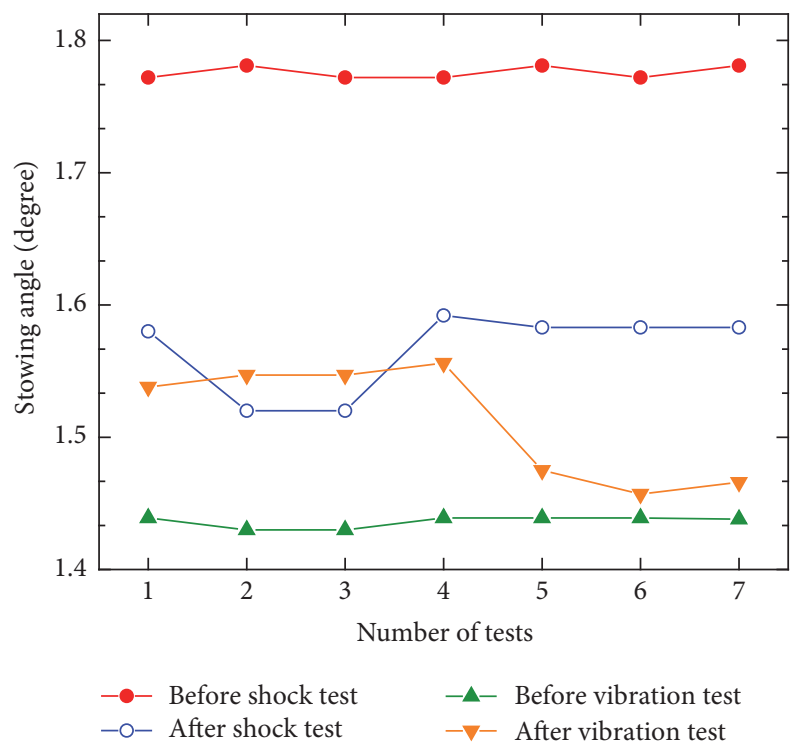

FIGURE 14: Measured stowing angle values before and after launch environment tests.

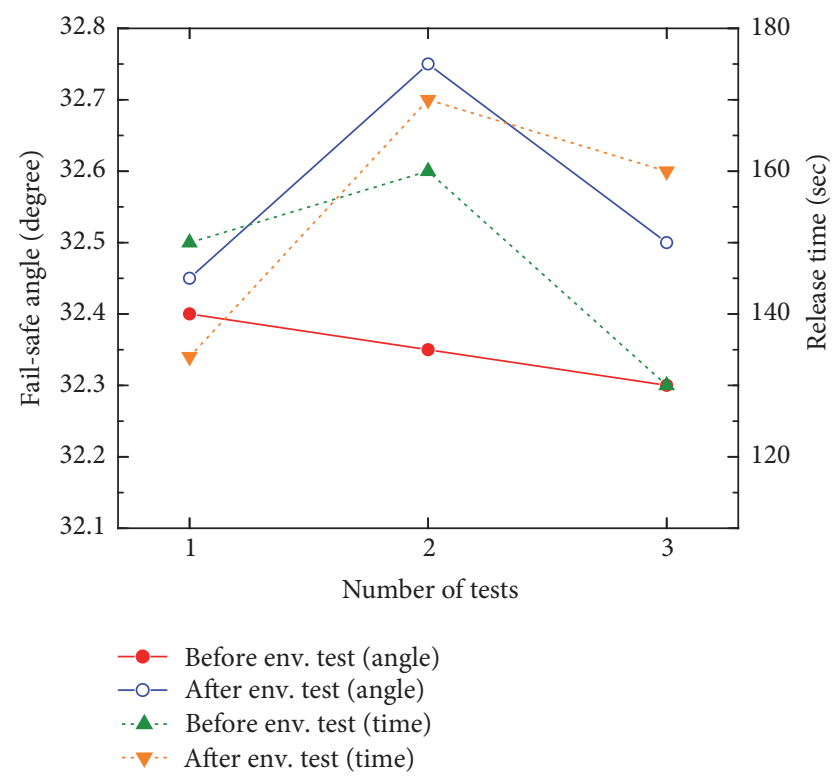

FIGURE 15: Measured fail-safe angle values before and after launch environment tests.

of imposing mechanical constraints on the driving part of the mechanism and providing a fail-safe function in launch and emergency phases. The main function of the mechanism is to deploy a driving structure module during calibration and stow it after calibration or an emergency phase to avoid blocking the main optical path for image acquisition. In addition, the function of launch constraint for the driving structure module in a launch environment can also be achieved without using the launch locking device generally used in a conventional mechanism. To validate the effectiveness of the mechanism design, operational function tests were performed. The mechanism was also exposed to the launch vibration environment and the measured angles for deploying, stowing, and fail-safe function of the mechanism were compared with those from before the vibration environment test. The test results indicated that the design approach proposed in this study is feasible for achieving the design goals of the tilting calibration mechanism.

\section{Conflicts of Interest}

The authors declare that they have no conflicts of interest.

\section{Acknowledgments}

This research was supported by the space core technology development program of the National Research Foundation of Korea (NRF) funded by the Ministry of Science, ICT \& Future Planning (MSIP) (NRF-2014M1A3A3A02034813).

\section{References}

[1] C. C. Walton, J. T. Sullivan, C. R. N. Rao, and M. P. Weinreb, "Corrections for detector nonlinearities and calibration inconsistencies of the infrared channels of the advanced very high resolution radiometer," Journal of Geophysical Research: Oceans, vol. 103, no. 2, Article ID 97JC02018, pp. 3323-3337, 1998.

[2] J. C. Bremer, "Alternative blackbody configurations for infrared calibration of future GOES Imagers and sounders," in Proceedings of International Symposium on Optical Science and Technology, vol. 4814 of Earth Observing Systems VII, pp. 183193, Seattle, Wash, USA, July 2002.

[3] A. Ono, F. Sakuma, K. Arai et al., "Preflight and in-flight calibration plan for ASTER," Journal of Atmospheric and Oceanic Technology, vol. 13, no. 2, pp. 321-335, 1996.

[4] V. I. Sapritsky, S. N. Mekhontsev, A. V. Prokhorov, K. A. Sudarev, V. B. Khromtchenko, and M. L. Samoilov, "Precision large area low and medium temperature blackbody sources," in Proceedings of the SPIE's International Symposium on Optical Science, Engineering, and Instrumentation, vol. 3437 of Infrared Spaceborne Remote Sensing VI, pp. 434-445, July 1998.

[5] X. Xiong, K. Chiang, J. Esposito, B. Guenther, and W. Barnes, "MODIS on-orbit calibration and characterization," Metrologia, vol. 40, no. 1, pp. S89-S92, 2003.

[6] H.-U. Oh, M.-S. Jo, K.-M. Lee, and D.-J. Kim, "Spaceborne tilt mirror mechanism and application of shape memory alloy actuator to implement fail-safe function in emergency mode," Transactions of the Japan Society for Aeronautical and Space Sciences, vol. 55, no. 6, pp. 373-378, 2012.

[7] J. Suchman, Y. Salinas, and H. Kubo, "MIRO calibration switch mechanism," in Proceedings of The 35th Aerospace Mechanisms Symposium, pp. 179-184, 2001.

[8] http://www.tiniaerospace.com.

[9] P. M. C. L. Pacheco and M. A. Savi, "A non-explosive release device for aerospace applications using shape memory alloys," in Proceedings of the XIV the Brazilian Congress of Mechanical Engineering (COBEM'97-ABCM), pp. 1-8, 1997.

[10] K. Yamauchi, I. Ohkata, K. Tsuchiya, and S. Miyazaki, Shape Memory and Superelastic Alloys: Technologies and Applications, Elsevier, 2011.

[11] A. K. Pandey, D. K. Setua, and G. N. Mathur, "Smart materials: an overview," in Proceedings of the Indo-Russian Workshop on Micromechanical Systems, vol. 3903, pp. 288-297, 1999. 
[12] J. Ma, H. Huang, and J. Huang, "Characteristics analysis and testing of SMA spring actuator," Advances in Materials Science and Engineering, vol. 2013, Article ID 823594, 7 pages, 2013.

[13] S. Degeratu, N. G. Bizdoaca, G. Manolea, I. Diaconu, A. Petrisor, and V. Degeratu, "On the design of a shape memory alloy spring actuator using thermal analysis," WSEAS Transactions on Systems, vol. 7, no. 10, pp. 1006-1015, 2008.

[14] G. H. Pan and W. M. Huang, "A note on constrained shape memory alloys upon thermal cycling," Journal of Materials Science, vol. 41, no. 23, pp. 7964-7968, 2006.

[15] http://www.saesgetters.com.

[16] W. Huang, "On the selection of shape memory alloys for actuators," Materials and Design, vol. 23, no. 1, pp. 11-19, 2002.

[17] European Cooperation for Space Standardization (ECSS-Q-ST30-02C), "Space Product Assurance, Failure Modes, Effects (and criticality) Analysis (FMEA/FMECA)".

[18] European Cooperation for Space Standardization (ECSS-E-ST33-01C): Mechanism.

[19] M. J. Lee, Y. K. Lee, and H. U. Oh, "Performance evaluation of hinge driving separation nut-type holding and releasing mechanism triggered by nichrome burn wire," International Journal of Aeronautical and Space Sciences, vol. 16, no. 4, pp. 602-613, 2015.

[20] L. An, W. M. Huang, Y. Q. Fu, and N. Q. Guo, "A note on size effect in actuating NiTi shape memory alloys by electrical current," Materials and Design, vol. 29, no. 7, pp. 1432-1437, 2008.

[21] W. Huang, "Modified shape memory alloy (SMA) model for SMA wire-based actuator design," Journal of Intelligent Material Systems and Structures, vol. 10, no. 3, pp. 221-231, 2000. 


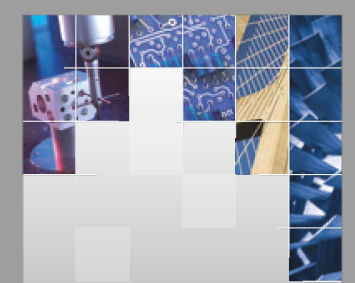

\section{Enfincering}
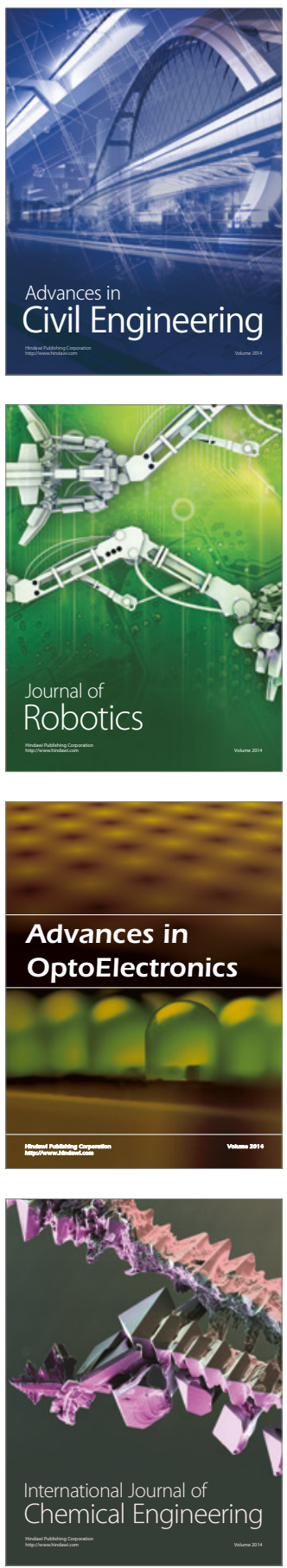

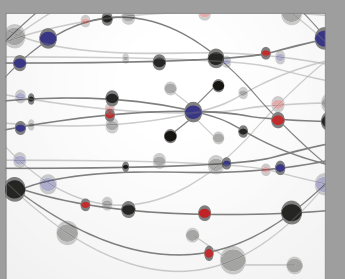

The Scientific World Journal

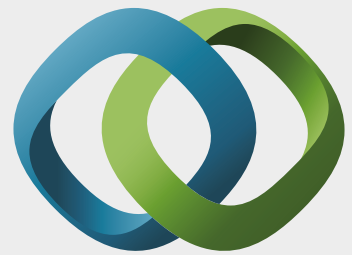

\section{Hindawi}

Submit your manuscripts at

https://www.hindawi.com
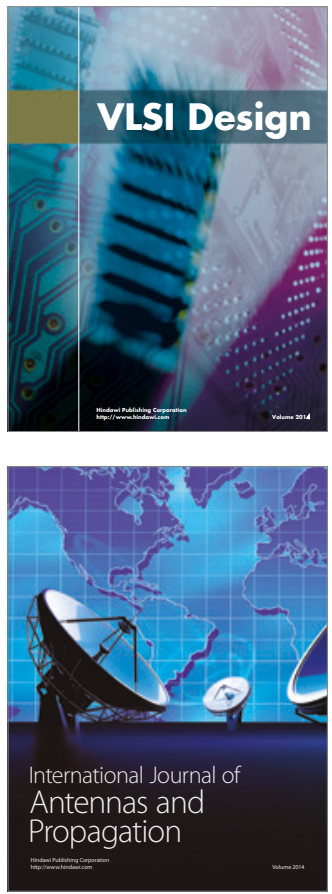

\section{Rotating}

Machinery
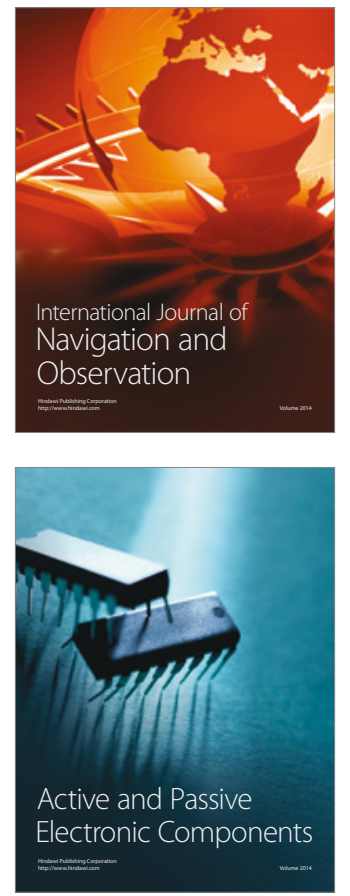
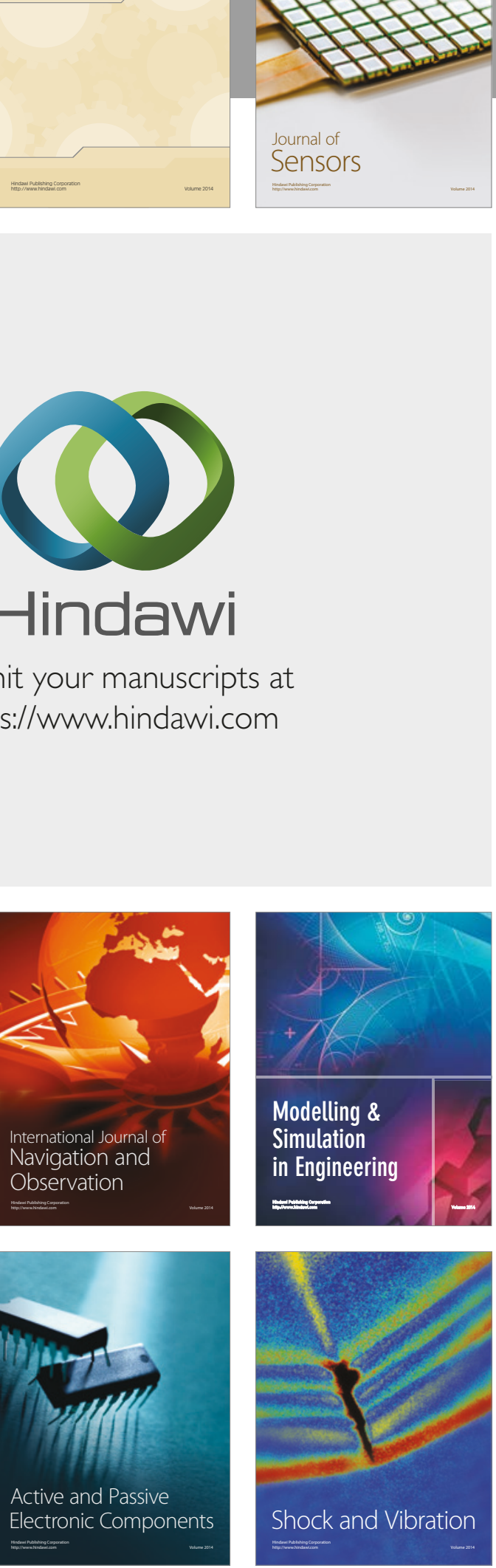
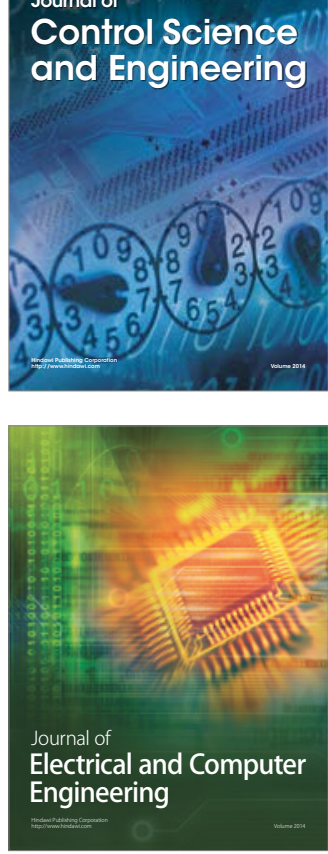

Distributed

Journal of

Control Science

and Engineering
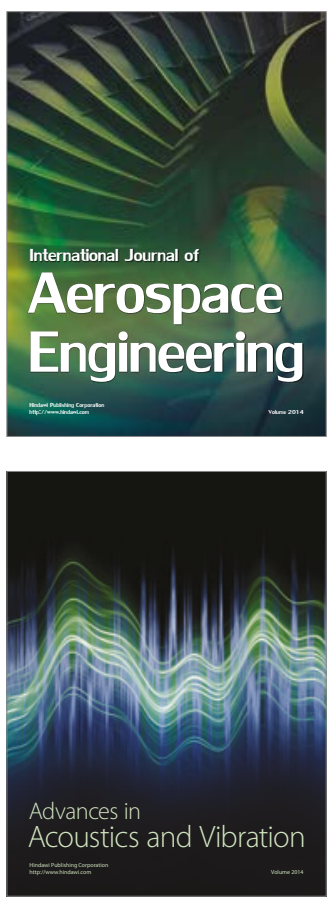

Sensor Networks 